\title{
Efektivitas Pengobatan Topikal pada Pitiriasis Versikolor
}

\author{
Andreas V. Pusung, ${ }^{1}$ Pieter L. Suling, ${ }^{2}$ Nurdjannah J. Niode ${ }^{2}$
}

\author{
${ }^{1}$ Program Studi Pendidikan Dokter Fakultas Kedokteran Universitas Sam Ratulangi Manado \\ Sulawesi Utara, Indonesia \\ ${ }^{2}$ Bagian Ilmu Kesehatan Kulit dan Kelamin Fakultas Kedokteran Universitas Sam Ratulangi \\ Manado, Sulawesi Utara, Indonesia \\ Email: andrepusung7@gmail.com
}

\begin{abstract}
Pityriasis versicolor is a chronic mild superficial fungal infection of the skin due to lipophilic fungi Malassezia. It commonly affects the face, neck, abdomen, proximal extremities, axilla, groin, and genitalia. The occurrence of this disease is not influenced by sex, albeit, age influences its incidence since it is more common in adolescents and young adults.Therefore, an effective, safe, and affordable treatment should be considered. The first-line therapy for pityriasis versicolor is topical treatment, classified into specific and non-specific antifungal agents. This study was aimed to determine the efficacy of topical treatment in pityriasis versicolor. This was a literature review study using three databases, namely PubMed, ClinicalKey, and Google Scholar and the keywords of "topical treatment AND pityriasis versicolor". The results obtained 10 literatures that fulfilled the inclusion and exclusion criteria. Theseliteratures discussed about the efficacy of topical treatment in patients with pityriasis versicolor based on clinical and mycological cure rate and the highest percentage was more than $80 \%$ in each study. In conclusion, topical treatment was effective for pityriasis versicolor.
\end{abstract}

Keywords: topical treatment, pityriasis versicolor

\begin{abstract}
Abstrak: Pitiriasis versikolor adalah penyakit jamur superfisial ringan akibat infeksi kulit kronis oleh jamur lipofilik genus Malassezia. Infeksi ini biasanya ditemukan pada wajah, leher, perut, ektremitas proksimal, aksila, lipat paha, dan genitalia. Kejadian penyakit ini tidak dipengaruhi oleh jenis kelamin, tetapi dapat dipengaruhi oleh usia, yaitu lebih banyak terjadi pada remaja dan dewasa muda. Pengobatan topikal merupakan terapi lini pertama untuk pitiriasis versikolor dan dibagi menjadi agen antijamur nonspesifik dan agen antijamur spesifik. Penelitian ini bertujuan untuk mengetahui efektivitas pengobatan topikal pada pitiriasis versikolor. Jenis penelitian ialah literature review dengan pencarian data menggunakan tiga database yaitu PubMed, ClinicalKey, dan Google Scholar. Kata kunci yang digunakan yaitu "topical treatment AND pityriasis versicolor". Hasil seleksi berdasarkan kriteria inklusi dan eksklusi mendapatkan 10 literatur. Kasjian literatur penelitian menunjukkan efektivitas penggunaan pengobatan topikal pada pitiriasis versikolor berdasarkan penyembuhan klinis maupun penyembuhan mikologis dengan persentase tertinggi mencapai angka $>80 \%$ pada masing-masing literatur. Simpulan penelitian ini ialah pengobatan topikal pada pitiriasis versikolor terbukti efektif.
\end{abstract}

Kata kunci: pengobatan topikal, pitiriasis versikolor

\section{PENDAHULUAN}

Pitiriasis versikolor adalah penyakit jamur superfisial ringan akibat infeksi kulit kronis oleh jamur lipofilik genus Malassezia. ${ }^{1}$ Infeksi ini biasanya ditemukan pada wajah, leher, perut, ektremitas proksimal, aksila, lipat paha dan genitalia. Kejadian penyakit ini tidak dipengaruhi oleh jenis kelamin, tetapi dapat dipengaruhi oleh usia, yaitu lebih banyak terjadi pada remaja dan dewasa muda. ${ }^{2}$

Di Indonesia, pitiriasis versikolor 
merupakan penyakit dengan kejadian terbanyak di antara penyakit kulit akibat jamur lainnya. ${ }^{2}$ Di Poliklinik Kulit dan Kelamin RSUP Prof. Dr. R. D. Kandou Manado, pada periode Januari-Desember 2013, terdapat 36 kasus $(0,87 \%)$ pitiriasis versikolor dengan jumlah terbanyak pada laki-laki sebanyak 21 kasus $(58,7 \%)$. Dari segi usia, jumlah terbanyak pada rentang usia 15-24 tahun dan 25-44 tahun yaitu masing-masing sebanyak 11 kasus $(30,6 \%)$. Berdasarkan warna lesi yang paling banyak ditemukan ialah lesi hipopigmentasi sebanyak 29 kasus $(80,6 \%)^{3}$

Pitiriasis versikolor bersifat rekuren atau dapat mengalami kekambuhan. Oleh karena itu, pemilihan pengobatan yang efektif, aman dan terjangkau harus dipertimbangkan. Pengobatan pitiriasis versikolor dapat dilakukan secara topikal dan sistemik. Pengobatan topikal merupakan terapi lini pertama untuk pitiriasis versikolor dan dibagi menjadi agen antijamur nonspesifik dan agen antijamur spesifik. Agen antijamur nonspesifik yang terbukti efektif untuk mengobati pitiriasis versikolor ialah selenium sulfid 2,5\% (sediaan losion, sampo, dan krim), zink pirition, propilen glikol, dan salep Whitfield. ${ }^{1}$ Penelitian terbaru juga menunjukkan efektivitas penggunaan gel adapalen, gel diklofenak, dan takrolimussebagai pengobatan nonspesifik pada pitiriasis versikolor. ${ }^{4-6}$ Agen antijamur spesifik ialah golongan imidazol (klotrimazol, ketokonazol, ekonazol, isokonazol, mikonazol, lulikonazol, eberkonazol dan dapakonazol)., ${ }^{1,-9}$ Ketokonazol merupakan pengobatan topikal yang paling umum digunakan untuk pitiriasis versikolor dan dapat ditemukan dalam bentuk krim atau sampo. Pengobatan sistemik dipandang sebagai pengobatan lini kedua untuk pitiriasis versikolor dengan infeksi yang berat. Obat antijamur oral atau sistemik ialah ketokonazol, itrakunazol, dan flukonazol. Keuntungan pengobatan topikal ialah kerjanya cepat dan memiliki risiko efek samping serius yang terbatas, sedangkan pengobatan sistemik cenderung memiliki efek samping yang serius. ${ }^{1,10}$

Berdasarkan latar belakang yang telah diuraikan, penulis tertarik untuk menelaah berbagai informasi ilmiah mengenai efektivitas pengobatan topikal pada pitiriasis versikolor.

\section{METODE PENELITIAN}

Penelitian ini merupakan suatu literature review. Data penelitian yang digunakan diperoleh dari tiga database yaitu PubMed, ClinicalKey, dan Google Scholar. Kata kunci yang digunakan dalam pencarian literatur yaitu topical treatment AND pityriasis versicolor. Kriteria inklusi dalam penelitian ini ialah populasi pasien pitiriasis versikolor, intervention pemberian pengobatan topikal, jenis penelitian clinical trial, randomized controlled trial, single blind, double blind, cross sectional, case control study, cohort study, tahun publikasi 2011 sampai 2020, serta berbahasa Inggris dan Indonesia. Kriteria eksklusi yakni populasi selain pasien pitiriasis versikolor dan literatur yang tidak tersedia fulltext.

\section{HASIL PENELITIAN}

Berdasarkan hasil pencarian literatur, didapatkan sebanyak 16 literatur menggunakan PubMed, 50 menggunakan Clinical Key, 1.900 menggunakan Google Scholar $(\mathrm{n}=1.966)$ yang sesuai dengan kata kunci tersebut. Hasil pencarian yang diperoleh kemudian dilakukan skrining berdasarkan judul literature review dan didapatkan 42 literatur $(\mathrm{n}=42)$. Selanjutnya 42 literatur tersebut dilakukan skrining berdasarkan kriteria inklusi dan eksklusi, dan didapatkan 10 literatur $(\mathrm{n}=10)$.

Tabel 1 memperlihatkan hasil kajian dari10 literatur yang digunakan dalam penelitian ini.

\section{BAHASAN}

Hasil penelitian ini menunjukkan bahwa penggunaan pengobatan topikal pada pitiriasis versikolor terbukti efektif. Penelitian yang dilakukan oleh Shi et al ${ }^{5}$ menunjukkan efektivitas krim ketokonazol $2 \%$ maupun gel adapalen $0,1 \%$ dalam pengobatan pitiriasis versikolor, dengan tingkat penyembuhan klinis dan mikologis pada masing-masing obat mencapai $>85 \%$. 
Tabel 1. Hasil kajian literatur yang dipakai dalam penelitian

\begin{tabular}{|c|c|c|c|c|c|}
\hline No. & $\begin{array}{c}\text { Nama } \\
\text { peneliti }\end{array}$ & $\begin{array}{c}\text { Jenis } \\
\text { penelitian }\end{array}$ & $\mathbf{N}$ & Intervensi & Hasil penelitian \\
\hline 1. & $\begin{array}{l}\text { Sharquie et } \\
\mathrm{al}^{4}\end{array}$ & Single blind & 75 & $\begin{array}{l}\text { Gel diklofenak } 1 \% \\
\text { pada } 25 \text { pasien, } \\
\text { krim } \\
\text { klotrimazol } 1 \% \\
\text { pada } 25 \text { pasien, dan } \\
\text { Placebo pada } 25 \\
\text { pasien. Masing- } \\
\text { masing diberikan } 2 \\
\text { kali sehari }\end{array}$ & $\begin{array}{l}\text { Berdasarkan respon penyembuhan total pada } \\
\text { minggu ke- } 2 \text {, terdapat perbedaan bermakna antara } \\
\text { kelompok diklofenak }(16 \%) \text { dan kelompok klotri- } \\
\text { mazol }(56 \%) \text { dengan nilai } \mathrm{p}=0,008 \text {. } \\
\text { Berdasarkan respon penyembuhan total pada } \\
\text { minggu ke-4, terdapat perbedaan bermakna } \\
\text { antara kelompok diklofenak }(56 \%) \text { dan kelom- } \\
\text { pok klotrimazol }(92 \%) \text { dengan nilai p=0,009. }\end{array}$ \\
\hline 2. & Shi et $\mathrm{al}^{5}$ & $\begin{array}{l}\text { Double blind, } \\
\text { randomized } \\
\text { controlled } \\
\text { trial }\end{array}$ & 67 & $\begin{array}{l}\text { Gel adapalene } 0,1 \% \\
\text { pada } 35 \text { pasien, dan } \\
\text { krim ketokonazol } \\
2 \% \text { pada } 32 \text { pasien. } \\
\text { Masing-masing } \\
\text { diberikan } 2 \text { kali } \\
\text { sehari }\end{array}$ & $\begin{array}{l}\text { Berdasarkan respon penyembuhan klinis pada } \\
\text { minggu ke- } 4 \text {, tidak terdapat perbedaan ber-makna } \\
\text { antara kelompok adapalen }(88,6 \%) \text { dan kelom- } \\
\text { pok ketokonazol }(87,5 \%) \text { dengan nilai p }=0,893 \text {. } \\
\text { Berdasarkan respon penyembuhan mikologis, } \\
\text { tidak terdapat perbedaan bermakna antara } \\
\text { kelompok adapalen }(85,6 \%) \text { dan kelompok } \\
\text { ketokonazol }(87,5 \%) \text { dengan nilai p= } 0,830 \text {. } \\
\text { Beberapa pasien mengalami efek samping } \\
\text { ringan, yaitu terdapat } 6 \text { pasien yang mengeluh } \\
\text { eritema, deskuamasi, kering kulit dan sensasi } \\
\text { terbakar pada kelompok adapalen dan } 5 \text { pasien } \\
\text { mengalami sensasi iritasi ringan pada kelompok } \\
\text { ketokonazol. }\end{array}$ \\
\hline 3. & Rad et $\mathrm{al}^{11}$ & $\begin{array}{l}\text { Single Blind, } \\
\text { Randomized }\end{array}$ & 90 & $\begin{array}{l}\text { Krim terbinafin } 1 \% \\
\text { pada } 48 \text { pasien, dan } \\
\text { krim } \\
\text { ketokonazol } 2 \% \\
\text { pada } 42 \text { pasien. } \\
\text { Masing-masing } \\
\text { diberikan } 2 \text { kali } \\
\text { sehari }\end{array}$ & $\begin{array}{l}\text { Berdasarkan penyembuhan total pada minggu ke- } \\
\text { 4, tidak terdapat perbedaan bermakna antara } \\
\text { kelompok terbinafin }(81,2 \%) \text { dan kelompok } \\
\text { ketokonazol }(69 \%) \text { dengan nilai p=0,8. } \\
\text { Hasil evaluasi minggu ke- } 8 \text {, terdapat tingkat } \\
\text { kekambuhan } 1,3 \% \text { pada kelompok terbinafin dan } \\
2,4 \% \text { pada kelompok ketokonazol. }\end{array}$ \\
\hline 4. & Shi et $\mathrm{al}^{12}$ & $\begin{array}{l}\text { Randomized } \\
\text { controlled } \\
\text { trial }\end{array}$ & 100 & $\begin{array}{l}\text { Gel adapalene } 0,1 \% \\
+ \text { krim ketokonazol } \\
2 \% \text { pada } 50 \text { pasien, } \\
\text { dan krim } \\
\text { Ketokonazol } \\
2 \% \text { pada } 50 \text { pasien. } \\
\text { Masing-masing } \\
\text { diberikan } 2 \text { kali } \\
\text { sehari }\end{array}$ & $\begin{array}{l}\text { Berdasarkan penyembuhan total pada minggu ke- } \\
2 \text {, terdapat perbedaan bermakna antara kelom- } \\
\text { pok kombinasi }(88 \%) \text { dan kelompok monoterapi } \\
(56 \%) \text { dengan nilai } \mathrm{p}=0,000 \text {. } \\
\text { Berdasarkan penyembuhan total pada minggu ke- } \\
4 \text {, terdapat perbedaan bermakna antara kelom- } \\
\text { pok kombinasi }(92 \%) \text { dan kelompok monoterapi } \\
(72 \%) \text { dengan nilai } \mathrm{p}=0,009 \text {. } \\
\text { Beberapa pasien mengalami efek samping } \\
\text { ringan, yaitu } 5 \text { pasien mengalami eritema, kulit } \\
\text { kering, atau sensasi terbakar pada kelompok } \\
\text { kombinasi, dan } 3 \text { pasien mengalami iritasi ringan } \\
\text { pada kelompok monoterapi. }\end{array}$ \\
\hline 5. & Gobbato $^{7}$ & $\begin{array}{l}\text { Double blind, } \\
\text { randomized }\end{array}$ & 53 & $\begin{array}{l}\text { Krim ketokonazol } \\
2 \% \text { pada } 26 \text { pasien, } \\
\text { dan krim } \\
\text { dapakonazol } \\
\text { tosylate } 1 \% \text { krim, } \\
\text { pada } 27 \text { pasien. } \\
\text { Masing-masing } \\
\text { diberikan } 2 \text { kali } \\
\text { sehari }\end{array}$ & $\begin{array}{l}\text { Berdasarkan penyembuhan klinis pada minggu } \\
\text { ke- } 4 \text {, tidak terdapat perbedaan bermakna antara } \\
\text { kelompok ketokonazol }(84 \%) \text { dan kelompok } \\
\text { dapakonazol tosylate }(92,6 \%) \text { dengan nilai } \\
\text { p=0,126. }\end{array}$ \\
\hline 6. & $\begin{array}{l}\text { Sharkar et } \\
\mathrm{al}^{8}\end{array}$ & $\begin{array}{l}\text { Randomized } \\
\text { controlled } \\
\text { trial }\end{array}$ & 80 & $\begin{array}{l}\text { Krim ketokonazol } \\
2 \% \text { pada } 40 \text { pasien, } \\
\text { dan krim } \\
\text { lulikonazol } 1 \%\end{array}$ & $\begin{array}{l}\text { Berdasarkan penyembuhan klinis pada minggu } \\
\text { ke- } 2 \text {, tidak terdapat perbedaan bermakna antara } \\
\text { kelompok ketokonazol }(67,5 \%) \text { dan kelompok } \\
\text { lulikonazol }(80 \%) \text { dengan nilai } \mathrm{p}=0,217 \text {. }\end{array}$ \\
\hline
\end{tabular}




\begin{tabular}{|c|c|c|c|c|c|}
\hline & & & & $\begin{array}{l}\text { pada } 40 \text { pasien. } \\
\text { Masing-masing } \\
\text { diberikan } 2 \text { kali } \\
\text { sehari }\end{array}$ & $\begin{array}{l}\text { Berdasarkan peyembuhan klinis pada minggu ke- } \\
\text { 4, terdapat perbedaan bermakna antara kelompok } \\
\text { ketokonazol }(72,5 \%) \text { dan kelompok lulikonazol } \\
(92,5 \%) \text { dengan nilai } \mathrm{p}=0.036 \text {. }\end{array}$ \\
\hline 7. & 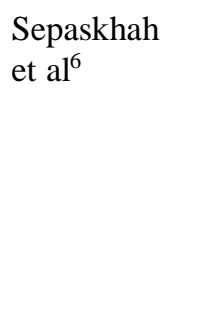 & $\begin{array}{l}\text { Single blind, } \\
\text { randomized }\end{array}$ & 45 & $\begin{array}{l}\text { Krim klotrimazol } \\
1 \% \text { pada } 20 \text { pasien, } \\
\text { dan krim } \\
\text { takrolimus } 0,03 \% \\
\text { pada } 25 \text { pasien. } \\
\text { Masing-masing } \\
\text { diberikan } 2 \text { kali } \\
\text { sehari }\end{array}$ & $\begin{array}{l}\text { Berdasarkan penyembuhan klinis pada minggu } \\
\text { ke- } 5 \text {, tidak terdapat perbedaan bermakna antara } \\
\text { kelompok klotrimazol }(84 \%) \text { dan kelompok } \\
\text { takrolimus }(84 \%) \text { dengan nilai p }=0,45 \text {. Berda- } \\
\text { sarkan penyembuhan total, tidak terdapat perbe- } \\
\text { daan bermakna antara kelompok klotrimazol } \\
(56 \%) \text { dan kelompok takrolimus }(56 \%) \text { dengan } \\
\text { nilai } p=0,63 \text {. }\end{array}$ \\
\hline 8. & $\begin{array}{l}\text { Sharma et } \\
\mathrm{al}^{9}\end{array}$ & $\begin{array}{l}\text { Open label, } \\
\text { randomized }\end{array}$ & 60 & $\begin{array}{l}\text { Krim Eberkonazol } \\
1 \% \text { pada } 30 \text { pasien, } \\
\text { dan krim } \\
\text { terbinafin } 1 \% \text { pada } \\
30 \text { pasien. Masing- } \\
\text { masing diberikan } 1 \\
\text { kali sehari }\end{array}$ & $\begin{array}{l}\text { Berdasarkan penyembuhan klinis pada minggu } \\
\text { ke- } 2 \text {, tidak terdapat perbedaan bermakna antara } \\
\text { kelompok eberkonazol }(80 \%) \text { dan kelompok } \\
\text { terbinafin }(63,3 \%) \text { dengan nilai p }>0,05 \text {. Berda- } \\
\text { sarkan penyembuhan mikologis, tidak ter-dapat } \\
\text { perbedaan bermakna antara kelompok eberko- } \\
\text { nazol }(100 \%) \text { dan kelompok terbinafin }(96,6 \%) \\
\text { dengan nilai } p=0,313 \text {. }\end{array}$ \\
\hline 9. & Swadi et $\mathrm{al}^{13}$ & $\begin{array}{l}\text { Randomized } \\
\text { controll trial }\end{array}$ & 40 & $\begin{array}{l}\text { Gel diklofenak } 1 \% \\
\text { pada } 20 \text { pasien, dan } \\
\text { krim } \\
\text { klotrimazol } 1 \% \\
\text { pada } 20 \text { pasien. } \\
\text { Masing-masing } \\
\text { diberikan } 2 \text { kali } \\
\text { sehari }\end{array}$ & $\begin{array}{l}\text { Berdasarkan penyembuhan klinis pada minggu } \\
\text { ke-2, terdapat perbedaan bermakna antara kelom- } \\
\text { pok diklofenak }(20 \%) \text { dan kelompok klotrimazol } \\
(65 \%) \text { dengan nilai p=0,008. Berdasarkan } \\
\text { penyembuhan mikologis, terdapat perbedaan } \\
\text { bermakna antara kelompok diklofenak (20\%) dan } \\
\text { kelompok klotrimazol ( } 70 \%) \text { dengan nilai } \\
\text { p=0,001. } \\
\text { Berdasarkan penyembuhan klinis pada minggu } \\
\text { ke- } 4 \text {, terdapat perbedaan bermakna antara kelom- } \\
\text { pok diklofenak (50\%) dan kelompok klotrimazol } \\
(90 \%) \text { dengan nilai p=0,019. Berdasarkan } \\
\text { penyembuhan mikologis, tidak terdapat perbeda- } \\
\text { an bermakna antara kelompok diklofenak }(65 \%) \\
\text { dan kelompok klotrimazol }(90 \%) \text { dengan nilai } \mathrm{p} \\
=0,058 \text {. }\end{array}$ \\
\hline 10. & Bakr et al ${ }^{14}$ & Randomized & 90 & $\begin{array}{l}\text { Krim ketokonazol } \\
2 \% \text { pada } 30 \text { pasien, } \\
\text { gel adapalene } 0,1 \% \\
\text { pada } 30 \text { pasien, dan } \\
\text { gel adapalene } 0,1 \% \\
\text { (malam hari ) } \\
\text { dengan krim } \\
\text { ketokonazol } 2 \% \\
\text { (siang hari) pada } 30 \\
\text { pasien. Masing- } \\
\text { masing diberikan } 2 \\
\text { kali sehari }\end{array}$ & $\begin{array}{l}\text { Berdasarkan penyembuhan klinis pada minggu } \\
\text { ke-2, terdapat perbedaan bermakna antara ketiga } \\
\text { kelompok masing-masing }(30 \%, 20 \%, 56,7 \%) \\
\text { dengan nilai p=0,023. Berdasarkan penyembuhan } \\
\text { mikologis, tidak terdapat perbedaan bermakna } \\
\text { antara ketiga kelompok masing-masing }(40 \% \text {, } \\
36,6 \%, 53,3 \%) \text { dengan nilai } \mathrm{p}=0,39 \text {. } \\
\text { Berdasarkan penyembuhan klinis pada minggu } \\
\text { ke-4, tidak terdapat perbedaan bermakna antara } \\
\text { ketiga kelompok masing-masing }(83,3 \%, 70 \% \text {, } \\
\text { 93,3\%) dengan nilai p=0,11. Berdasarkan pe- } \\
\text { nyembuhan mikologis, terdapat perbedaan ber- } \\
\text { makna antara ketiga kelompok masing-masing } \\
(70 \%, 60 \%, 86,6 \%) \text { dengan nilai } \mathrm{p}=0,024 \text {. }\end{array}$ \\
\hline
\end{tabular}

Penelitian oleh Shi et $\mathrm{al}^{12}$ menunjukkan efektivitas dari kombinasi krim ketokonazol $2 \%$ dan gel adapalen $0,1 \%$ pada pengobatan pitiriasis versikolor, dengan tingkat penyembuhan total mencapai $92 \%$. Hasil tersebut sejalan dengan pene- litian Bakr et $\mathrm{al}^{14}$ yang mendapatkan tingkat penyembuhan klinis sebesar 93,3\% dan penyembuhan mikologis sebesar $86,6 \%$ pada penggunaan kombinasi krim ketokonazol $2 \%$ dan gel adapalen $0,1 \%$ dalam pengobatan pitiriasis versikolor. 
Penelitian oleh Sharkar et $\mathrm{al}^{8}$ menunjukkan efektivitas krim lulikonazol $1 \%$ berdasarkan penyembuhan klinis mencapai 92,5\%. Selain itu pada hasil penelitian Gobbato $^{7}$ menunjukkan krim dapakonazol tosylate juga efektif dalam pengobatan pitiriasis versikolor dengan penyembuhan klinis mencapai 92,6\%.

Penelitian Sharquie et $\mathrm{al}^{4}$ menunjukkan efektivitas dari krim klotrimazol $1 \%$ yang dibandingkan dengan gel diklofenak $1 \%$ dalam pengobatan pitiriasis versikolor. Berdasarkan penelitian tersebut, krim klotrimazol cenderung lebih efektif dengan tingkat penyembuhan total mencapai $92 \%$. Hasil tersebut sejalan dengan penelitian oleh Swadi et $\mathrm{al}^{13}$ yang mendapatkan efektivitas krim klotrimazol $1 \%$ berdasarkan penyembuhan klinis dan mikologis mencapai $90 \%$.

Penggunaan krim takrolimus $0,03 \%$ terbukti sama efektif dengan krim klotrimazol $1 \%$ dalam pengobatan pitiriasis versikolor. Penelitian oleh Sepaskhah et $\mathrm{al}^{6}$ mendapatkan hasil penyembuhan klinis pada kelompok takrolimus dan klotrimazol masing-masing sebesar $84 \%(\mathrm{p}=0,45)$.

Berdasarkan hasil penelitian oleh Rad et al, ${ }^{11}$ krim terbinafin $1 \%$ sama efektifnya dengan krim ketokonazol $2 \%$ dalam pengobatan pitiriasis versikolor. Hasil penelitian tersebut menunjukkan penyembuhan total pada kelompok terbinafin mencapai $81,2 \%$.

Pada penelitian yang dilakukan oleh Sharma et al, ${ }^{9}$ penggunan krim eberkonazol $1 \%$ mempunyai respon yang lebih baik dibandingkan dengan krim terbinafim $1 \%$ dalam pengobatan pitiriasis versikolor. Hasil peneltian tersebut menunjukkan tingkat penyembuhan klinis pada kelompok eberkonazol mencapai $80 \%$ dan penyembuhan mikologis mencapai $100 \%$.

\section{SIMPULAN}

Pengobatan topikal pada pitiriasis versikolor terbukti efektif. Pengobatan topikal yang memiliki efektivitas terbaik ialah krim eberkonazol $1 \%$ dengan waktu penyembuhan selama 2 minggu yang dapat menghasilkan penyembuhan klinis setinggi $80 \%$ dan penyembuhan mikologis setinggi
$100 \%$ serta tidak dilaporkan adanya efek samping selama penggunaan obat tersebut.

\section{Konflik Kepentingan}

Penulis menyatakan tidak terdapat konflik kepentingan dalam studi ini.

\section{DAFTAR PUSTAKA}

1. Bramono K, Budimulja U. Nondermatofitosis. In: Menaldi, Linuwih SSW, editors. Ilmu Kesehatan Kulit dan Kelamin (7th ed). Jakarta: Fakultas Kedokteran Universitas Indonesia, 2019; p. 103-4.

2. Bramono K, Suyoso S, Indriatmi W, Ramali LM, Widaty S, Ervianty E. Dermatomikosis Superfisialis (2nd ed). Jakarta: Fakultas Kedokteran Universitas Indonesia, 2013; p. 24-32.

3. Isa DYF, Niode NJ, Pandaleke HEJ. Profil pitiriasis versikolor di Poliklinik Kulit dan Kelamin RSUP Prof. Dr. R. D. Kandou Manado periode JanuariDesember 2013. e-CliniC. 2016;4(2).

4. Sharquie KE, Al-Hamamy HM, Noaimi AA, Al-Shawi IA. Treatment of pityriasis versicolor using $1 \%$ diclofenac gel and clotrimazole cream (comparative therapeutic study). Journal of the Saudi Society of Dermatology \& Dermatologic Surgery. 2011;15(1):19-23.

5. Shi TW, Ren XK, Yu HX, Tang YB. Roles of adapalene in the treatment of pityriasis versicolor. Dermatology. 2012;224(2): 184-8.

6. Sepaskhah M, Sadat MS, Pakshir K, Bagheri Z. Comparative efficacy of topical application of tacrolimus and clotrimazole in the treatment of pityriasis versicolor: a single blind, randomised clinical trial. Mycoses. 2017;60(5):1-5.

7. Alves A, Gobbato M, Babadópulos T, Aparecida C, Gobbato RS, Ilha JDO, et al. A randomized double-blind, noninferiority phase II trial, comparing dapaconazole tosylate $2 \%$ cream with ketoconazole $2 \%$ cream in the treatment of pityriasis versicolor. Expert Opinion on Investigational Drugs (EOIDR). 2015;24(11):1399-407

8. Sarkar S, Sengupta D, Basak S, Damji S, Shukla D, Anurag D. Comparative assessment of the efficacy of topical ketoconazole and topical luliconazole in cases of pityriasis versicolor at a tertiary care hospital in eastern India: a 
prospective, open, randomized controlled trial. Indian Dermatology Online Journal. 2016;7(4):335.

9. Sharma J, Kaushal J, Aggarwal K. A Comparative study of efficacy and safety of eberconazole versus terbinafine in patients of tinea versicolor. Indian Journal of Dermatology. 2020;63(1): 53-6.

10. Gupta AK, Foley KA. Antifungal treatment for pityriasis versicolor. Journal of Fungi. 2015;1(1):13-29.

11. Rad F, Nik-Khoo B, Yaghmaee R, Gharibi F. Terbinafin $1 \%$ cream and ketoconazole $2 \%$ cream in the treatment of pityriasis versicolor: a randomized comparative clinical trial. Pakistan Journal of Medical Sciences. 2014; 30(6):1273-6.
12. Shi TW, Zhang JA, Tang YB, Yu HX, Li ZG, $\mathrm{Yu}$ JB. A randomized controlled trial of combination treatment with ketoconazole $2 \%$ cream and adapalene $0.1 \%$ gel in pityriasis versicolor. J Dermatol Treat. 2015;26(2):143-6.

13. Swadi AAJ, Jabur AH. The value of diclofenac gel $1 \%$ in the treatment of pityriasis versicolor in a sample of Iraqi patients. Int J Pharm Res. 2019;11(3): 25-8.

14. Bakr E, Abdo H, Abd-Elaziz H, Abd-Elrazek $\mathrm{H}$, Amer M. Adapalene gel $0.1 \%$ vs ketoconazole cream $2 \%$ and their combination in treatment of pityriasis versicolor: a randomized clinical study. Dermatol Ther. 2020;33(3):4-9. 